\title{
Perspectives for 2013
}

\author{
Cid Aimbiré M. Santos \\ Editor-in-chief
}

We have reached the last issue in 2012 of the Brazilian Journal of Pharmacognosy (RBFAR), and we have a lot to celebrate. We had a particularly difficult year, because we could not receive resources from the $\mathrm{CNPq} /$ CAPES/MCT publishing program, which requires that all journals be Qualis CAPES B2 stratum; moreover, we had been B3 until last year. However, we received support from INCT-if, which kindly offered us the resources to publish issue \#1 with thirty articles by solely Brazilian authors. This issue also benefitted from the Brazilian Society of Pharmacognosy itself and authors who voluntarily contributed to the journal. To these authors, we give special thanks.

Although we have had some difficulties, 2012 was a year of growth. We started using the ScholarOne Manuscripts System, reduced the average reply time to the authors from 48 days to 32 days, and lowered the publication's submission time from 507 days in 2010 to 266 days in 2012 .

According to the academic community that believes in the RBFAR, the journal's most important achievement was the data recently published by Scopus, ${ }^{1}$ which raised us to the Q2 category and increased our $\mathrm{H}$ index to 18 . The self-citations have drastically reduced, and the number of scholars who cite our articles is now increasing at a more constant rate, moving towards the consolidation of RBFAR. We hope that with this new data, the RBFAR will achieve a level of credibility with Thomson Reuters that will guarantee our Impact Factor's disclosure for next year.

Nevertheless, we have yet to make an acknowledgement to the authors who believe in the RBFAR and to all of those who have made it their vehicle of publication. Recently, the Third Seminar on The Performance of Brazilian Journals in the JCR 2011, promoted by the SciELO Brasil program, ${ }^{2}$ concluded that the difficulty faced by the Brazilian scientific journals to improve their Impact Factor in the international scene is due to the low number of Brazilian articles that they have published in collaboration with foreign authors. In addition, we believe the following obstacles can be added to this list of difficulties: 1. The financing agencies' pleas to Brazilian authors to publish in high-impact journals; and 2. The fact that Brazilian scientists do not submit their best manuscripts to Brazilian journals as their primary choice.

We believe these two factors are the main obstacles to the growth of national journals. On one hand, the agencies' requirements encourage Brazilian scientists to submit their manuscripts to major international journals first; on the other hand, there is a cultural perception that we have been taught to under-appreciate our own periodicals; thus, many scientists will look to Brazilian scientific journals as the last option to publish their results, even if they conducted the research in Brazil. Hence, the Brazilian periodicals very often receive manuscripts that were not successfully accepted by journals overseas or articles from authors who already know that they cannot earn acceptance abroad. Undoubtedly, there is a correlation between the impact of a journal and its excellency in research; however, we must first believe in the potential of Brazilian journals before they can grow enough to impact in the international scene of the periodicals that we publish.

We are thankful to the CNPq/CAPES/MCT publishing programs, which have worked hard to cherish the Brazilian scientific journals; furthermore, Brazilian journals would benefit from an additional policy that compels Brazilian researchers to make our journals their first publishing choice; consequently, the Brazilian scientific journals would increase their impact factor. If the Brazilian scientists believe in our journal, then the RBFAR will, in turn, set the following goals for next year: providing quicker visibility to the accepted articles and discovering new ways to divulge the journal internationally by attending events such as congresses, symposia, and workshops and by using social networking, among other activities. Furthermore, if scientists back us, we will release issues related to relevant themes with more frequency. We will also launch a special issue as our first issue in 2013 and it will feature 25 articles in the field of Phytopharmaceutical Technology. In addition, we will call for papers for an edition on Ethnopharmacology.

To the authors who had their articles published in RBFAR in 2012, we give our sincere gratitude. You have contributed to the journal's growth, and we hope we have also been able to support your graduate programs not only with the publication of an article but also through the evaluation and discussion of each submission with the reviewers and editors.

Our hope is that the correlation between the impact of a journal and its excellency in research, which we have so thoroughly disclosed, will be a reality for the Brazilian Journal of Pharmacognosy and for all Brazilian scientific journals in the years to come. 